\title{
F-box protein complex FBXL19 regulates TGF $\beta 1$-induced E-cadherin down-regulation by mediating Rac3 ubiquitination and degradation
}

Su Dong ${ }^{1,2,3}$, Jing Zhao ${ }^{3}$, Jianxin Wei ${ }^{3}$, Rachel K Bowser ${ }^{3}$, Andrew Khoo ${ }^{3}$, Zhonghui Liu ${ }^{1 \dagger}$, James D Luketich$^{4}$, Arjun Pennathur ${ }^{4}$, Haichun $\mathrm{Ma}^{2+}$ and Yutong Zhao ${ }^{3^{*+}}$

\begin{abstract}
Background: Rac3 is a small GTPase multifunctional protein that regulates cell adhesion, migration, and differentiation. It has been considered as an oncogene in breast cancer; however, its role in esophageal cancer and the regulation of its stability have not been studied. F-box proteins are major subunits within the Skp1-Cullin-1-Fbox (SCF) E3 ubiquitin ligases that recognize particular substrates for ubiquitination and proteasomal degradation. Recently, we have shown that SCF ${ }^{\mathrm{FBX} 19}$ targets Rac1 and RhoA, thus regulating Rac1 and RhoA ubiquitination and degradation. Here, we demonstrate the role of FBXL19 in the regulation of Rac3 site-specific ubiquitination and stability. Expression of TGF $\beta 1$ is associated with poor prognosis of esophageal cancer. TGF $\beta 1$ reduces tumor suppressor, E-cadherin, expression in various epithelial-derived cancers. Here we investigate the role of FBXL19mediated Rac3 degradation in TGF $\beta 1$-induced E-cadherin down-regulation in esophageal cancer cells.
\end{abstract}

Methods: FBXL19-regulated endogenous and over-expressed Rac3 stability were determined by immunoblotting and co-immunoprecipitation. Esophageal cancer cells (OE19 and OE33) were used to investigate TGF $\beta 1$-induced E-cadherin down-regulation by Immunoblotting and Immunostaining.

Results: Overexpression of FBXL19 decreased endogenous and over-expressed Rac3 expression by interacting and polyubiquitinating Rac3, while down-regulation of FBXL19 suppressed Rac3 degradation. Lysine166 within Rac3 was identified as an ubiquitination acceptor site. The FBXL19 variant with truncation at the N-terminus resulted in an increase in Rac3 degradation; however, the FBXL19 variant with truncation at the C-terminus lost its ability to interact with Rac3 and ubiquitinate Rac3 protein. Further, we found that Rac3 plays a critical role in TGF $\beta 1$-induced E-cadherin down-regulation in esophageal cancer cells. Over-expression of FBXL19 attenuated TGF $\beta 1$-induced E-cadherin down-regulation and esophageal cancer cells elongation phenotype.

Conclusions: Collectively these data unveil that FBXL19 functions as an antagonist of Rac3 by regulating its stability and regulates the TGF $\beta 1$-induced E-cadherin down-regulation. This study will provide a new potential therapeutic strategy to regulate TGF $\beta 1$ signaling, thus suppressing esophageal tumorigenesis.

Keywords: Small GTPase protein, Protein stability, E3 ligase, Ubiquitin-proteasome system, TGF $\beta 1$, E-cadherin

\footnotetext{
*Correspondence: zhaoy3@upmc.edu

${ }^{\dagger}$ Equal contributors

${ }^{3}$ Department of Medicine and the Acute Lung Injury Center of Excellence, University of Pittsburgh, 3459 Fifth Avenue, NW 628MUH, Pittsburgh 15213, PA, USA

Full list of author information is available at the end of the article
}



(c) 2014 Dong et al.; licensee BioMed Central Ltd. This is an Open Access article distributed under the terms of the Creative Commons Attribution License (http://creativecommons.org/licenses/by/4.0), which permits unrestricted use, distribution, and reproduction in any medium, provided the original work is properly credited. The Creative Commons Public Domain Dedication waiver (http://creativecommons.org/publicdomain/zero/1.0/) applies to the data made available in this article, unless otherwise stated. 


\section{Background}

Rac3 (ras-related C3 botulinum toxin substrate 3) is a member of the RhoGTPase family. In its active form, it is bound to GTP, whereas it is inactive in its GDPbound form. It has been well studied that activation of RhoGTPases is controlled by guanidine activating proteins (GEFs) that exchange bound GDP to GTP and by GTPase activating proteins (GAPs) that promote GTP hydrolysis. Rac3 is enriched in the brains but it also expressed in a wide range of tissues [1]. Aberrant activation of Rac3 has been recognized to be important in tumor proliferation in both breast cancer and prostate cancer [2,3]. Rac3 regulates a variety of cellular functions including adhesion, cell migration, and differentiation. The controversial effects of Rac3 on cell migration have been reported. Rac3 negatively regulates diapedesis of prostate cancer cell PC3, since knockdown of Rac3 using Rac3 specific siRNA increased migration of PC3 cells through a bone marrow endothelial cell layer [4]. In contrast, overexpression of Rac3 promotes estrogen-induced breast cancer cell migration [2]. Rac3 was found to be involved in breast cancer cell aggressiveness through the activation of NF- $\mathrm{kB}$ and Erk2. Inhibition of Rac3 caused an increase in TNF $\alpha$-induced apoptosis [5]. However, the role of Rac3 in the pathogeneses of esophageal cancer has not been studied.

Many posttranslational modifications, including ubiquitination, expand the size of the proteome exponentially and are pivotal in the regulation of protein stability [6-9]. The ubiquitin proteasome system (UPS) regulates protein ubiquitination, and therefore degradation and turnover, of many proteins vital of cellular regulation and function [10]. The UPS depends upon the action of three enzyme complexes. The E1 enzyme functions as an activator by creating a thioester bond between a cysteine of the E1 enzyme and the ubiquitin molecule via ATP hydrolysis. E2, known as the conjugating enzyme, then accepts the ubiquitin protein onto an active site cysteine. Finally, the E3 ligating enzyme complex is responsible for attachment of this ubiquitin protein to a lysine of the target protein [11]. Among the families of E3 ubiquitin ligases, the Skp1-Cullin-1-F-box protein (SCF) ligases complex is one of the largest. In this complex, the F-box protein is the substrate-recognition component $[12,13]$. F-box proteins have two main domains: an F-box motif and a substrate binding motif. F-box proteins use their F-box motif to bind to Skp1 and assemble the SCF ligase complex, whereas the substrate-binding motif is used for recognition and interaction with phosphorylated substrates [14]. Through an in silico search, the 'orphan' F-box protein FBXL19 has been identified and verified as an SCF E3 subunit [15]. Recently, we demonstrated that FBXL19 regulates interleukin (IL)-33 signaling by targeting its cognate receptor ST2L, for ubiquitination, which, in turn, triggers its proteasomal degradation to alter the innate immune response [16]. In addition to ST2L, we also found that Rac1 and RhoA are targets for FBXL19 and revealed new functions of FBXL19 in regulating cell migration, proliferation and cytoskeleton rearrangement $[17,18]$.

E-cadherin, a type I classical cadherin, is a key component in the formation of cell-cell adherens-type junctions in epithelial tissues [19-21]. A variety of studies in cancers, including hepatocellular carcinoma, squamous cell carcinomas of the skin, head and neck, and pancreatic cancer, have demonstrated that E-cadherin plays a critical role as a tumor suppressor [22-25]. E-cadherin is often down-regulated during carcinoma progression and metastatic spread of tumors [26,27]. Loss of E-cadherin changes cancer cell phenotype and facilitates the initial invasive behaviors of epithelial-derived cancer [28]. Transforming growth factor $\beta$ (TGF $\beta$ ), a pleiotropic cytokine comprised of three isoforms in mammalian cells, function as a tumor promoting mediator in the later stages of cancers $[29,30]$. TGF $\beta 1$ signaling has been shown to play an important role in down-regulation of E-cadherin. It appears, that many epithelial tumors escape growth inhibition by TGF $\beta 1$, and TGF $\beta 1$ secretion by cancer may contribute to late tumor progression $[31,32]$. It has been shown that TGF $\beta 1$ expression is higher in esophageal cancer tissues, compared to normal squamous epithelium and non-malignant Barrett's mucosa [33]. Over-expression of TGF $\beta 1$ in esophageal cancer is associated with advanced stage of disease and poor prognosis [34].

In this study, we demonstrate that Rac3 is a target protein of SCF ${ }^{\text {FBXL19 }}$ E3 ligase. FBXL19 regulates Rac3 stability by ubiquitinating Rac3 on lysine 166 residue. This is the first report to reveal that Rac3 is implicated in TGF $\beta 1$-induced E-cadherin down-regulation in esophageal cancer cells. Further, we found that overexpression of FBXL19 attenuates the effect of TGF $\beta 1$ on E-cadherin down-regulation. This study will provide a molecular basis for SCF E3 ligase in the regulation of esophageal tumorigenesis.

\section{Results}

\section{FBXL19 reduces Rac3 protein expression}

We have demonstrated that $\mathrm{SCF}^{\mathrm{FBXL19}}$ ligase targeted Rac1 and RhoA for its ubiquitination and degradation $[17,18]$. To investigate if the FBXL19 also regulates Rac3 degradation, we transfected with V5-tagged FBX L19 (FBXL19-V5) and hemagglutinin-tagged FBXL19 (FBXL19-HA) plasmids in HEK293 cells respectively. Both forms of tagged-FBXL19 down-regulated endogenous Rac3 expression (up to $73 \%$ ) (Figure 1A-B), while overexpression of other E3 ligase subunits (NEDD4L, FBXL18, and FBXL22) had no effect on Rac3 expression 




(Figure 1C). To determine the specificity of the Rac3 antibody, we examined the Rac3 and Rac1 expression in several cell lines including MLE12, HEK293, A549, and OE19 cells. As shown in Figure 1D, Rac3 was highly expressed in HEK293 and OE19 cells compared to its expression in A549 cells. It was not detectable in MLE12 cells. Rac1 was highly expressed all the cell lines, suggesting Rac3 antibody does not cross-react with Rac1 protein. Further, we examined if FBXL19 reduces over-expressed Rac3 levels. Since Rac3 is not detectable in MLE12 cells (Figure 1D), we used MLE12 cells for studying the stability of overexpressed Rac3. We co-overexpressed V5-tagged Rac3
(Rac3-V5) with different doses of FBXL19-V5 or FBXL19HA plasmid in MLE12 cells. Figure $1 \mathrm{E}$ and F show that the ectopic expression of FBXL19-V5 or FBXL19-HA diminished Rac3-V5 protein in a dose dependent manner. Further, we examined the effect of FBXL19 downregulation on Rac3-V5 expression. MLE12 cells were transfected with Rac3-V5 and three individual FBXL19 shRNAs. As shown in Figure 1G, FBXL19 shRNAs (\#2 and \#3 only) reduced FBXL19 expression (up to $\sim 50$ $70 \%)$, while Rac3-V5 protein mass was dramatically enhanced around 2.5 fold. To examine if the effect of FBXL19 on the reduction of Rac3 protein mass is due to 
modulation of Rac3 mRNA expression, we measured Rac3 mRNA levels by RT-realtime PCR. FBXL19-V5 had no effect on Rac3 mRNA expression, suggesting that FBXL19-mediated Rac3 reduction is through the regulation of Rac3 protein stability.

\section{FBXL19 induces Rac3 degradation in the proteasome system}

In the process of investigating the degradation of the Rac3 protein, we examined if Rac3 degradation is mediated in the ubiquitin-proteasome system. We found that administration of FBS-free (blank) medium diminished Rac3-V5 in a time-dependent manner (Figure 2A). To identify which pathway is involved in the degradation of Rac3, Rac3-V5 overexpressed cells were treated with inhibitors of proteasomes (MG-132) or lysosomes (leupeptin) prior to administration of blank medium. Starvation-mediated
Rac3 degradation was attenuated by pretreatment with MG-132 (up to $\sim 67 \%$ at $4 \mathrm{~h}$ ), but not leupeptin (Figure 2A), suggesting Rac3 degradation is mediated in the proteasome system, but not in the lysosome system. In addition, we found that the FBXL19-V5-induced Rac3 degradation was attenuated by MG-132 (up to 45-53\%), but not by leupeptin (Figure 2B). The results were confirmed by treating cells with other inhibitors of the proteasome (Lactacystin) or lysosome ( $\mathrm{NH} 4 \mathrm{Cl})$ (Figure 2B). To further investigate the role of FBXL19 in the regulation of Rac3 degradation, we down-regulated FBXL19 by FBXL19 shRNA transfection prior to treatment with blank medium. Figure $2 \mathrm{C}$ shows that FBXL19 shRNA transfection attenuated blank medium-mediated Rac3-V5 degradation (up to $\sim 64 \%$ at $4 \mathrm{~h}$ ), as well as FBXL19 expression (Figure 2C). The results suggest that FBXL19-mediated Rac3 degradation is in the proteasome system.

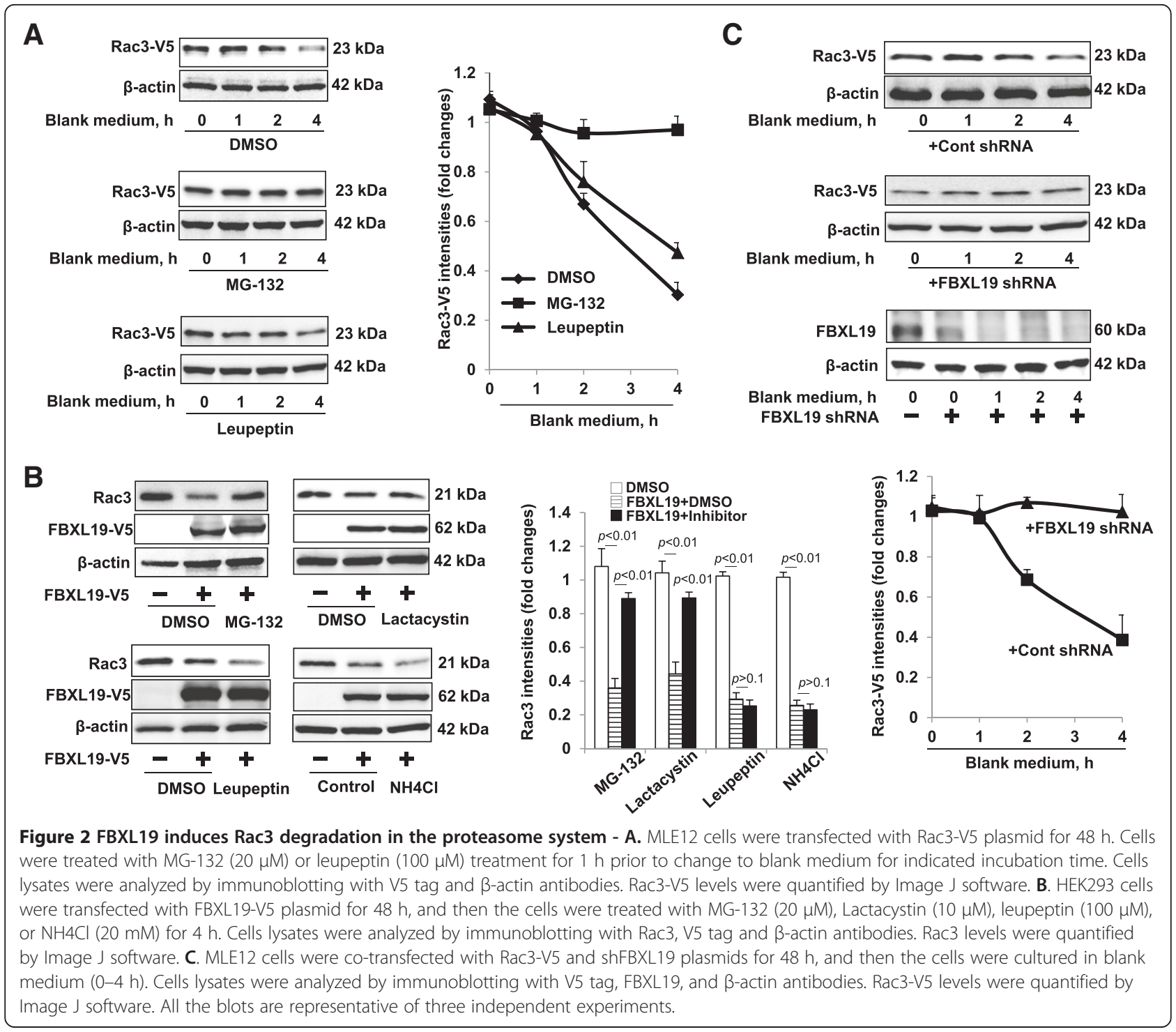


FBXL19 targets Rac3 lysine ${ }^{166}$ for ubiquitination

To investigate if FBXL19 is associated with Rac3, we overexpressed V5-tagged FBXL19 and Flag-tagged Rac3 in HEK293 cells. Immunoprecipitation (IP) with an antibody to the Flag tag followed by Western blotting with an antibody to the V5 tag revealed that FBXL19-V5 associates with Rac3-Flag (Figure 3A). Further, endogenous Rac3 was detected in the FBXL19-V5 immunoprecipitation complex (Figure 3B). To examine if FBXL19 induces Rac3 ubiquitination, cells were transfected with Rac3-V5 and FBXL19-HA plasmids. Co-IP with an antibody to ubiquitin followed by Western blotting with V5 tag immunoblotting demonstrated that overexpression of FBXL19 increased polyubiquitination of Rac3 (Figure 3C). Lysine (K) residues within a target protein are ubiquitin acceptor sites for linking mono- or polyubiquitin [35]. To identify the putative ubiquitin acceptor site within Rac3 for FBXL19, we substituted several candidate $K$ residues of Rac3 with arginine (R). Of several mutants tested, only $\mathrm{Rac} 3^{\mathrm{K} 166 \mathrm{R}}-\mathrm{V} 5$, not Rac3 ${ }^{\mathrm{K} 183 \mathrm{R}}-\mathrm{V} 5$ or Rac3 ${ }^{\mathrm{K} 184 \mathrm{R}}-\mathrm{V} 5$, was resistant to FBXL19mediated degradation (Figure 4A). Further, we compared the degree of ubiquitination of Rac3 wild type and Rac3 ${ }^{\text {K166R }}$-V5 after incubation with MG-132. As shown in Figure 4B, polyubiquitinated Rac3 was immunoprecipitated by an antibody to ubiquitin, and Rac3 K166R exhibits less ubiquitination, compared to Rac3 wild type, suggesting that K166 is an ubiquitin acceptor site within Rac3.

\section{Role of N-terminus and C-terminus of FBXL19 in Rac3 degradation}

Next we examined which part of FBXL19 is important in Rac3 degradation. Transfection of a plasmid encoding an FBXL19 variant with truncation at the NH2 (N111 or N121) resulted in increases in Rac3 degradation, compared to the wild type FBXL19-V5 (Figure 5A). This indicates that there is an inhibitory domain within the N-terminus of FBXL19. Further, an FBXL19 variant with truncation at the $\mathrm{COOH}(\mathrm{C} 450)$ lost the ability to degrade Rac3 (Figure 5B). In addition, co-IP with an antibody to the V5 tag revealed that wide type FBXL19-V5, but not the variant with truncation at the $\mathrm{COOH}(\mathrm{C} 450)$, associates with Rac3-Flag in HEK293 cells (Figure 5C). It suggests that Rac3 interacts with FBXL19 in the C-terminus of FBXL19.

\section{Rac3 regulates TGF $\beta 1$-induced E-cadherin down-regulation}

TGF $\beta 1$ is associated with poor prognosis of esophageal cancer [34]. TGF $\beta 1$-mediated down-regulation of Ecadherin contributes to tumor invasion and proliferation [31]. Here, we show that TGF $\beta 1$ treatment (4 days) induces E-cadherin down-regulation in a dose dependent

\section{A}
IP: Flag

IB: V5

62 kDa

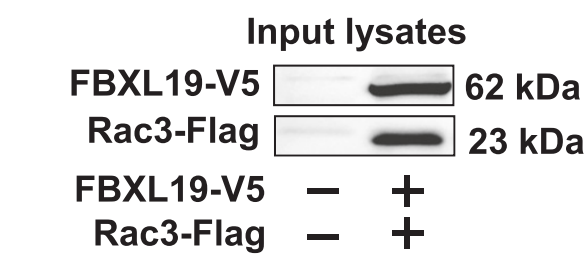

B

IP: V5

IB: Rac3

Input lysates

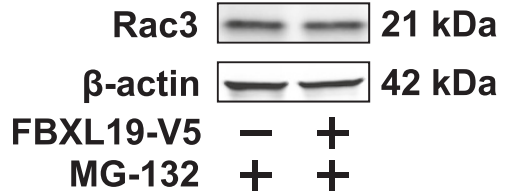

C

IP: Ubiquitin

IB: Rac3-V5

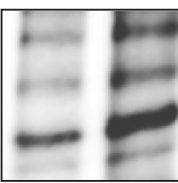

37 kDa $30 \mathrm{kDa}$ $23 \mathrm{kDa}$

Input lysates

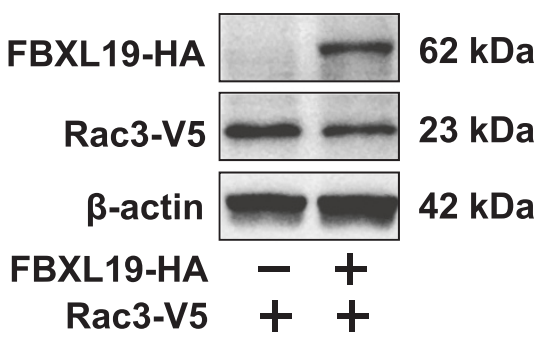

Figure 3 FBXL19 targets Rac3 for ubiquitination - A. HEK293 cells were co-transfected with Flag tagged Rac3 (Rac3-Flag) and FBXL19-V5 plasmids. Cell lysates were subjected to immunoprecipitation with a Flag tag antibody, followed by V5 tag immunoblotting. Input lysates were analyzed by immunoblotting with V5 tag and Flag tag antibodies. B. HEK293 cells were transfected with FBXL19-V5 plasmid followed by MG-132 $(20 \mu \mathrm{M})$ treatment. Cell lysates were subjected to immunoprecipitation with a V5 tag antibody, followed by Rac3 immunoblotting. Input lysates were analyzed by immunoblotting with Rac3 and $\beta$-actin antibodies. C. MLE12 cells were co-transfected with Rac3-V5 and FBXL19-HA plasmids. Cell lysates were subjected to immunoprecipitation with an ubiquitin antibody, followed by V5 tag immunoblotting. Input lysates were analyzed by immunoblotting with $\mathrm{HA}$ tag, V5 tag and $\beta$-actin antibodies. All the blots are representative of three independent experiments. 

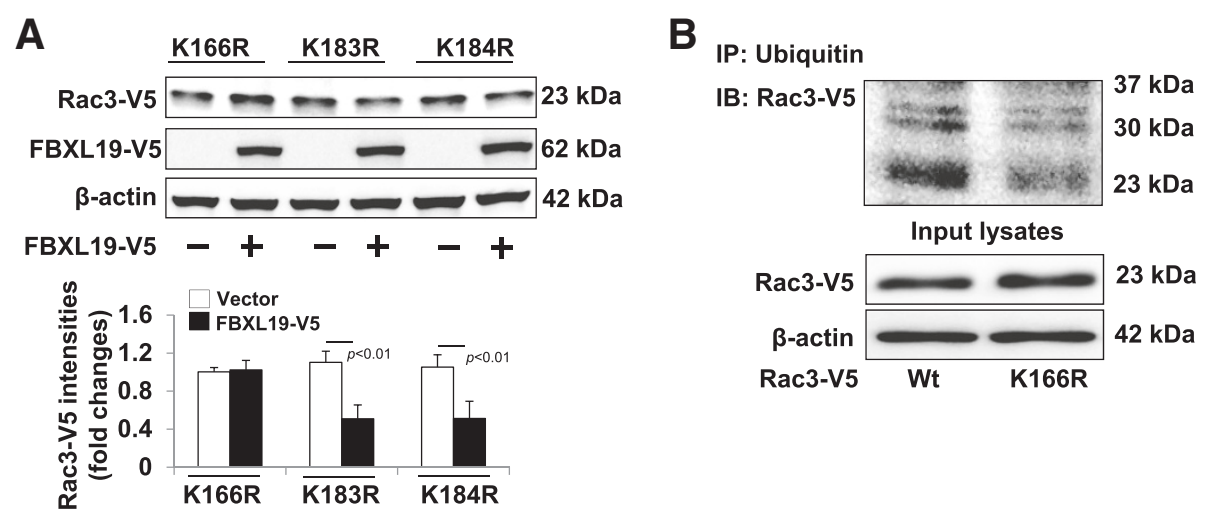

Figure 4 Lysine 166 within Rac3 is an ubiquitin acceptor site for FBXL19 - A. MLE12 cells were co-transfected with FBXL19-V5 wild type and Rac3 lysine mutant plasmids as indicated. Cell lysates were analyzed by immunoblotting with antibodies to V5 tag and $\beta$-actin. Rac3-V5 levels were quantified by Image J software. B. MLE12 cells were transfected with Wt Rac3-V5 or Rac3 ${ }^{\text {K166R }}$-V5 plasmid. Cell lysates were subjected to immunoprecipitation with an ubiquitin antibody, followed by V5 tag immunoblotting. Input lysates were analyzed by immunoblotting with V5 tag and $\beta$-actin antibodies. All the blots are representative of three independent experiments.

manner in esophageal cancer cell line OE19 (Figure 6A). Further, we found that TGF $\beta 1$ reduced E-cadherin expression in another esophageal cancer cell line OE33 (up to $\sim 69 \%$ ) (Figure 6A). To investigate if TGF 31 -mediated E-cadherin down-regulation is associated with Rac3, we overexpressed Rac3 inactive form (Rac3N17-V5) (Figure 6B) or down-regulation of Rac3 by transfection with Rac3 shRNA (Figure 6C) to inhibit Rac3 activity prior to TGF $\beta 1$ treatment $(0,2.5,5.0 \mathrm{ng} / \mathrm{ml}, 4$ days $)$ in OE19 cells. Both the Rac3 inactive form and Rac3 shRNA attenuated the TGF 1 1-reduced E-cadherin level (up to $\sim 34-37 \%$ ) (Figure $6 \mathrm{~B}$ and C). Snail, a transcriptional factor, is well known to down-regulate E-cadherin. Here, we found that over-expression of Rac3-V5 increased Snail expression by $\sim 1.95$ fold in OE19 cells (Figure 6D). Immunostaining showed that TGF $\beta 1$ treatment induced OE19 cell elongation phenotype was attenuated by over-expression of Rac3N17 (Figure 6E and F). These results suggest that Rac3 is involved in TGF 31 -induced E-cadherin down-regulation.

\section{FBXL19 regulates TGF $\beta 1$-induced E-cadherin} down-regulation

We have shown that FBXL19 mediates Rac3 degradation and Rac3 is involved in E-cadherin down-regulation by TGF $\beta 1$. Further, we examined if FBXL19 regulates TGF $\beta 1$-induced E-cadherin down-regulation. First, we confirmed the effect of FBXL19 in Rac3 degradation in

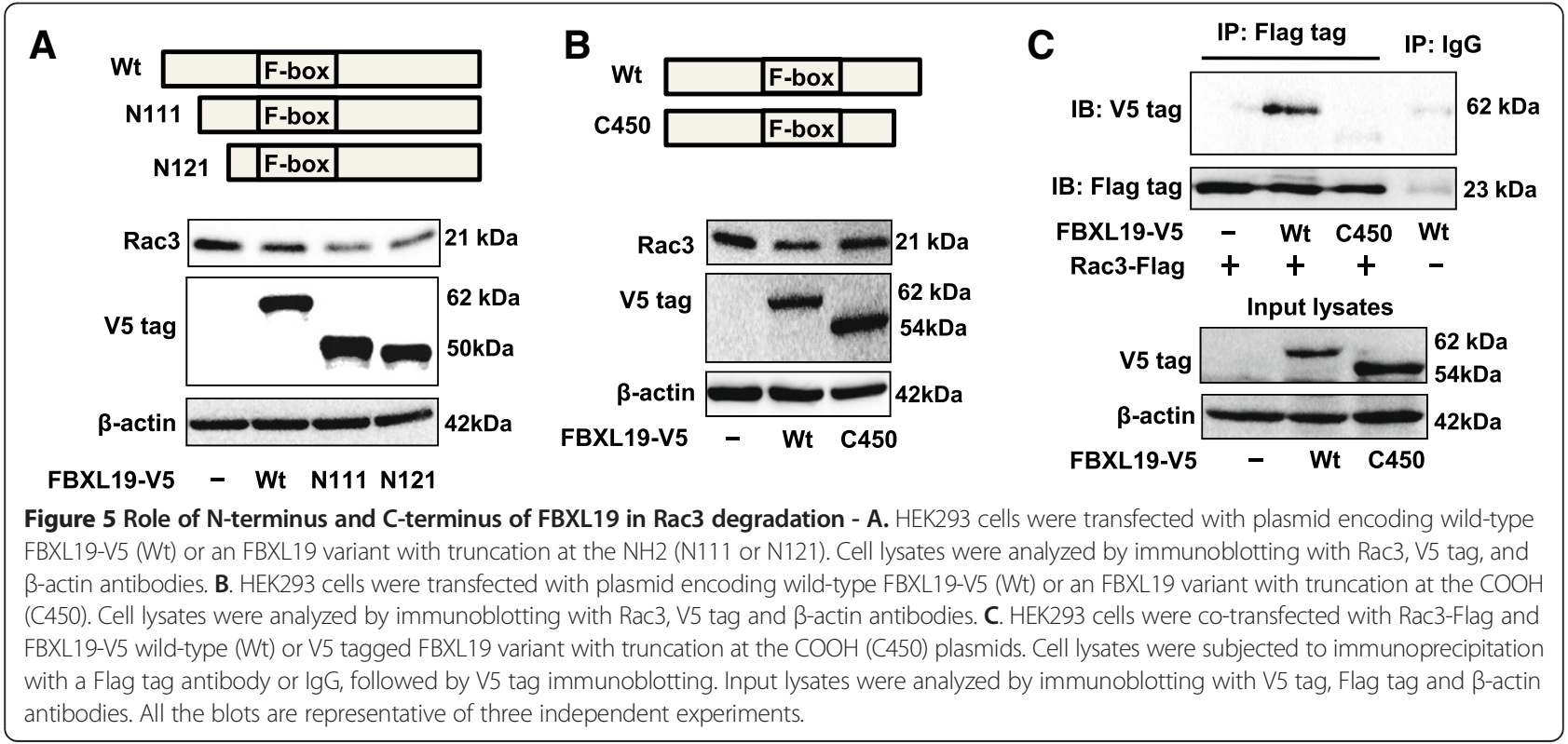






OE19 and OE33 (up to 53\%) cells. As shown in Figure 7A, FBXL19-V5 diminished Rac3 protein in a dose dependent manner in OE19, as well as in OE33 cells. As expected, we found that FBXL19-V5 reduced Rac3 activity in both OE19 and HEK293 cells (up to 6489\%) (Figure 7B). Next, we overexpressed FBXL19-V5 in OE19 and OE33 cells for $24 \mathrm{~h}$ prior to TGF $\beta 1$ treatment $(0,2.5,5.0 \mathrm{ng} / \mathrm{ml}, 4$ days $)$. Figure $7 \mathrm{C}$ shows that FBXL19-V5 attenuated the TGF 31 -induced decrease of E-cadherin (up to $\sim 36 \%$ with TGF $\beta 15 \mathrm{ng} / \mathrm{ml}$ treatment). These results were also observed in OE33 cells (up to 62\%) (Figure 7D). Further, we examined the effect of FBXL19-V5 on Rac3-mediated Snail expression. As shown in Figure 7E, FBXL19 blocked Rac3-V5 induced
Snail expression (up to $\sim 92 \%$ reduction) in OE19 cells. In addition, immunostaining showed that TGF $\beta 1$ treatment induced OE19 cell elongation phenotype was attenuated by over-expression of FBXL19 (Figure 7F and G) in OE19 cells. These results indicate that FBXL19 attenuates the effects of TGF $\beta 1$ on E-cadherin downregulation and cell elongation phenotype by mediating Rac3 degradation.

\section{Discussion}

Rho family GTPases are important intracellular signaling proteins that control diverse cellular functions, including actin cytoskeletal organization, migration and invasion, transcriptional regulation, cell cycle progression, 


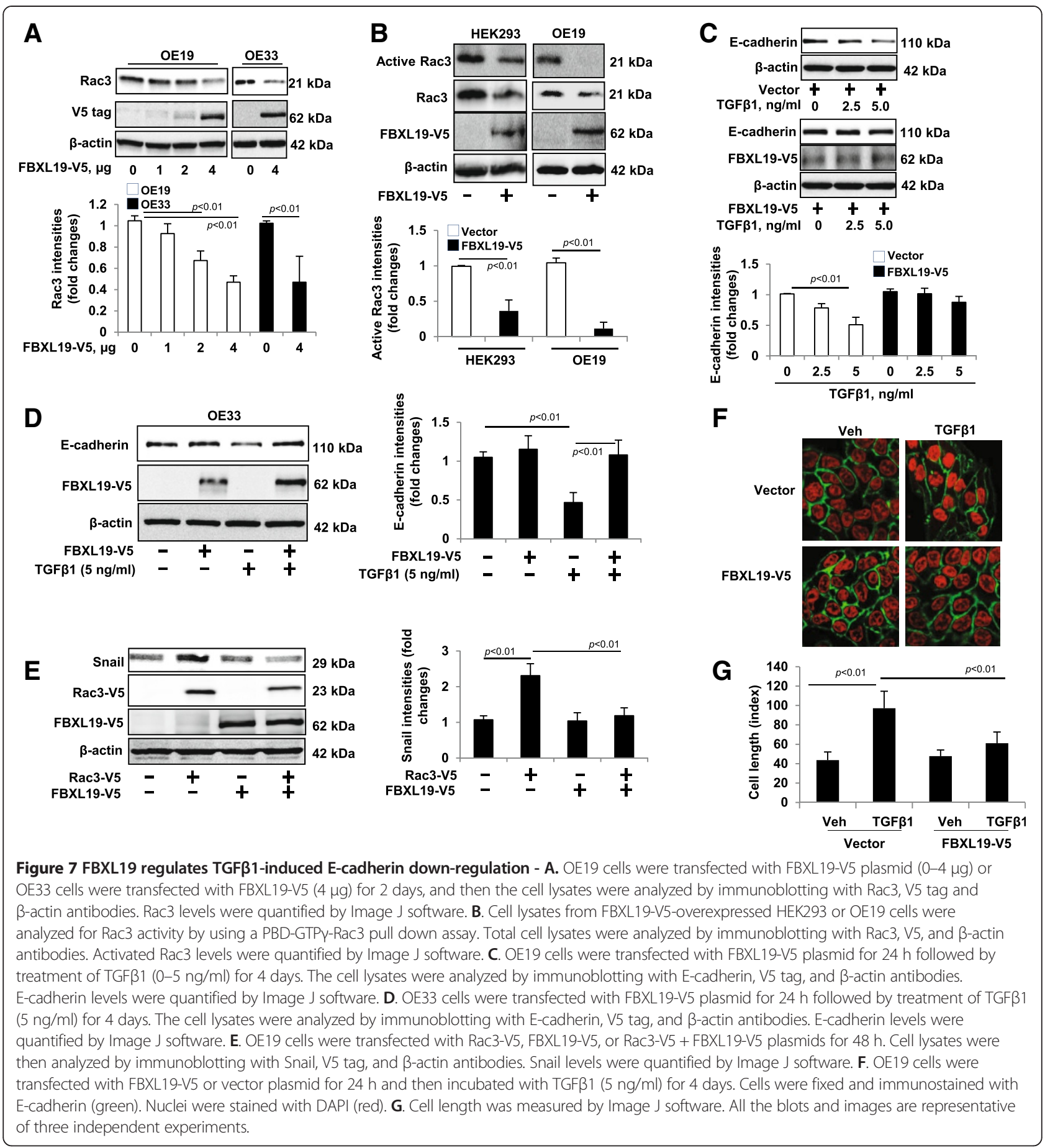

apoptosis, vesicle trafficking, and cell-to-cell and cell-toextracellular matrix adhesions [36,37]. Of the Rho family GTPases, Rac3 is implicated in regulating cell adhesion, growth, differentiation, and autophagy [38]. To date, little is known regarding the molecular regulation of Rac3 stability. Here, we show that Rac3 lifespan is regulated by the $\mathrm{SCF}^{\mathrm{FBXL} 19}$ E3 ligase and the proteasome system. FBXL19 targets Rac3 for ubiquitination in a specific lysine site, thus resulting in its degradation. Rac3, as an oncogene protein, plays a pivotal role in tumorgenesis of a variety type of cancers, including breast cancer and prostate cancer. This study is the first to report that Rac3 regulates TGFß1-mediated E-cadherin down-regulation in esophageal cancer cells, indicating a critical role of Rac3 in the progress of esophageal cancer. Further, we demonstrate that FBXL19 negatively regulates Rac3-mediated TGF $\beta 1$ 
signaling in esophageal cancer. Here, we provide new evidence that ubiquitin E3 ligase contributes to the tumorgenesis of esophageal cancer. Targeting the ubiquitin E3 ligase will build a basis to develop a new potential therapeutic strategy to inhibit tumor growth and invasion. Despite the high homology in amino-acid sequence between Rac1 and Rac3, Rac3 differs from Rac1 in the $\mathrm{COOH}$ terminal region, which is involved in Rac localization and regulatory protein binding [1]. However, most of literature addressing the role of Rac in cancer progression concern Rac1, with little mention of Rac3. The elucidation of mechanisms for control of Rac3 protein stability therefore might have important implications for metastasis.

Post-translational modifications, including ubiquitination, regulate the function of key signaling proteins by modulating their activity, localization, and protein stability. Ubiquitination of small GTPases controls their behavior in cells, including migratory ability and cell cycle progression. We established recently that FBXL19 targets RhoA and Rac1 for ubiquitination and degradation, thus regulating cell growth, stress fiber formation, and cell migration $[17,18]$. F-box proteins have been shown to target multiple-substrates. For example, FBXW7 ubiquitinates multiple proteins involved in different signal pathways, such as Notch, cyclin, c-Myc and c-Jun, for ubiquination and degradation [39-41]. Here we uncover that Rac3 is a new substrate for FBXL19 and it interacts with C-terminus of FBXL19. This is the first study to investigate Rac3 ubiquitination and degradation. Overexpression of FBXL19 reduced Rac3 for disposal. In addition, we identified that FBXL19 induced Rac3 ubiquitination at lysine ${ }^{166}$. This acceptor site is similar to Rac1 ubiquitin acceptor site from FBXL19, which is distant from GTP binding site and resides within a Cterminal $\alpha$-helix distinct from the polybasic tail [42]. It has been shown that other ubiquitin E3 ligases such as IAP and HACE1 also target Rac1 for ubiquitination and degradation. Since Rac3 shares a high homology with Rac1, the future study will focus on the role of IAP or HACE1 in regulation of Rac3 stability.

E-cadherin down-regulation is a fundamental biological process where epithelial cells lose their polarity and adopt morphology appropriate for migration [25]. Several studies have shown that E-cadherin downregulation is important in cancer progression and is associated with poor outcome in several tumor sites, including non-small cell lung cancer, invasive ductal breast carcinoma, and gastric adenocarcinoma [43,44]. In tumors of the esophagus and gastroesophageal junction, disturbances in E-cadherin expression have been correlated with increasing invasive capacity, dedifferentiation, and lymph node metastases [45]. E-cadherin downregulation occurs by canonical TGF $\beta 1$ signaling, which alters the function of the E-cadherin transcriptional repressor Snail directly. Rac1 has been known to regulate TGF 1 1-mediated signaling; however, the role of Rac3 in TGF $\beta 1$-induced E-cadherin has not been studied. Rac3 is abundantly present in developing and adult brains, and mildly expressed in the heart, placenta and pancreas. Hajdo-Milasinovic, A. et al. demonstrated that Rac3 inhibited adhesion of neuronal cells [46], indicating Rac3 may regulate E-cadherin expression. In this study, we show that Rac3 is strongly expressed in esophageal carcinoma cells and it regulates Snail expression. Interestingly, inhibition of Rac3 by overexpressed inactive form of Rac3 (Rac3N17), Rac3 shRNA, or FBXL19 significantly attenuates TGF $\beta 1$-induced E-cadherin downregulation (Figure 8). This study discovered that Rac3 plays an important role in the progress of esophageal cancer cells and the FBXL19 may function as a tumor suppressor through its ability to reduce Rac3 levels and inhibits TGF $\beta 1$ pathway. Future studies will be conducted to investigate the expression of Rac3 and FBXL19 in esophageal cancer tissues and adjacent normal tissues.

\section{Conclusions}

In summary, the current study unveils Rac3 as a new molecular target of FBXL19. FBXL19 targets Rac3 for ubiquitination in lysine 166 and induces its proteasomal degradation. Inhibition of Rac3 by FBXL19 modulates Ecadherin expression in esophageal cancer cells. This is the first evidence to support that Rac3 plays a critical role in the tumorgenesis of esophageal cancer and that FBXL19 exhibits an anti-tumor property by downregulation of small GTPase.

\section{Material and methods}

\section{Cells and reagents}

Esophageal adenocarcinoma (OE19 and OE33) cancer cells [Sigma-Aldrich (St. Louis, MO, USA)] were cultured with RPMI 1640 medium containing $2 \mathrm{mM}$ glutamine and 10\% FBS. HEK293 cells [Invitrogen (Carlsbad, CA, USA)] were cultured with DMEM medium containing 10\% FBS. Murine lung epithelia (MLE12) cells [American Type Culture Collection (ATCC), Manassas, VA, USA] were cultured with HITES medium containing 10\% FBS. All the cells were cultured at $37^{\circ} \mathrm{C}$ in $5 \% \mathrm{CO} 2 . \mathrm{V} 5$ antibody, E-cadherine antibody, mammalian expressional plasmid pcDNA3.1D/His V5 TOPO, Escherichia coli Top 10 competent cells, and recombinant TGF $\beta 1$ were from Invitrogen (Carlsbad, CA, USA). HA tag (29 F4), Flag tag (9A3), and ubiquitin (P4D1) antibodies were from Cell Signaling Technology (Danvers, MA, USA). Rac3 antibody was from Proteintech Group (Chicago, IL, USA). FBXL19 antibody was from Abgent (San Diego, CA, USA). Leupeptin, ammonium chloride ( $\mathrm{NH} 4 \mathrm{Cl}), \beta$-actin antibody, individual FBXL19 shRNAs, and scrambled shRNA were from 


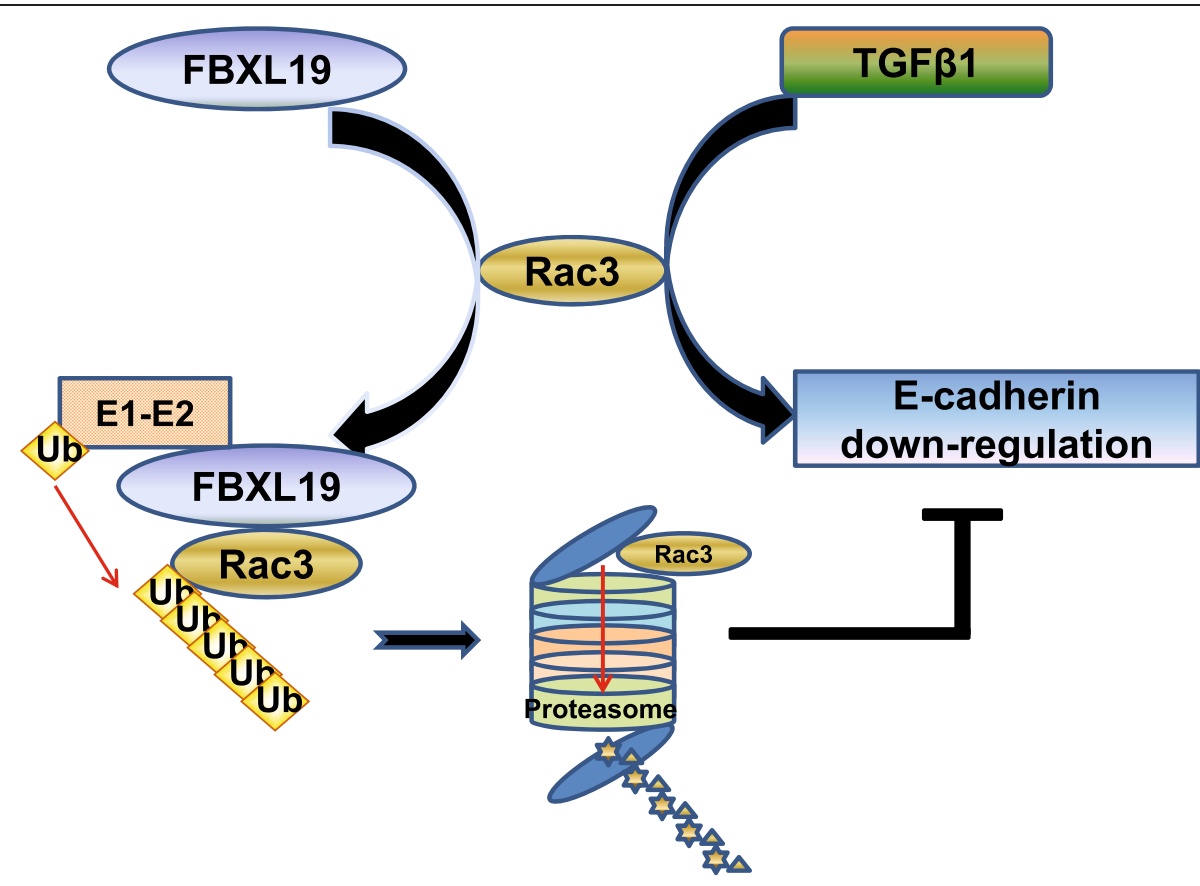

Figure 8 FBXL19 regulates TGF $\beta$ 1-induced E-cadherin down-regulation via targeting Rac3 for its degradation - FBXL19 regulates Rac3 degradation in the proteasome system. TGF $\beta 1$ induces E-cadherin down-regulation. Over-expression of FBXL19 reduces Rac3 level, thereby inhibiting TGF $\beta 1$-induced E-cadherin down-regulation.

Sigma Aldrich (St. Louis, MO, USA). MG132 and lactacystin from Calbiochem (La Jolla, CA, USA). Immunobilized protein $\mathrm{A} / \mathrm{G}$ beads were from Santa Cruz Biotechnology (Santa Cruz, CA, USA). Superfect transfection reagent was from QIAGEN (Valencia, CA, USA). All materials in highest grades uses in the experiments are commercially available.

\section{Construction of FBXL19 and Rac3 plasmids}

The FBXL19 cDNA was inserted into a pcDNA3.1D/V5His vector (Invitrogen, CA, USA). Site directed mutagenesis was performed to generate Rac3 lysine or serine mutant according to the manufacturer's instructions (Agilent Technologies, Santa Clara, CA, USA).

\section{Immunoblotting and immunoprecipitation}

Cells were washed with cold PBS and collected in cell lysis buffer containing $20 \mathrm{mM}$ Tris $\mathrm{HCl}$ (pH 7.4), $150 \mathrm{mM} \mathrm{NaCl}, 2 \mathrm{mM}$ EGTA, $5 \mathrm{mM} \beta$ glycerophosphate, $1 \mathrm{mM} \mathrm{MgCl} 2$, 1\% Trison X100, $1 \mathrm{mM}$ sodium orthovanadate, $10 \mu \mathrm{g} / \mathrm{ml}$ protease inhibitors, $1 \mu \mathrm{g} / \mathrm{ml}$ leupeptin, and $1 \mu \mathrm{g} / \mathrm{ml}$ pepstatin. An equal amount of cell lysates $(20 \mu \mathrm{g})$ was subjected to SDS-PAGE, electrotransferred to membranes and immunoblotted as described previously $[17,18]$. For immunoprecipitation, equal amounts of cell lysates $(1 \mathrm{mg})$ were incubated with specific primary antibodies overnight at $4^{\circ} \mathrm{C}$, followed by the addition of $40 \mu \mathrm{l}$ of protein $\mathrm{A} / \mathrm{G}$ agarose and incubation for additional $2 \mathrm{~h}$ at $4^{\circ} \mathrm{C}$. The immunoprecipitated complex was washed 3 times with 1\% Triton X100 in ice cold phosphate-buffered saline and analyzed by immunoblotting with indicated antibodies.

\section{Immunostaining}

OE19 cells were plated on $35 \mathrm{~mm}$ glass-bottom culture dishes. After treatment, cells were fixed in $3.7 \%$ formaldehyde for $20 \mathrm{~min}$, followed by permeabilization with $0.1 \%$ Triton X100 for $2 \mathrm{~min}$. Cells were incubated with 1:200 dilution of E-cadherin, followed by a 1:200 dilution of fluorescence-conjugated secondary antibody sequentially for immunostaining. Immunofluorescent cell imaging was performed on a Nikon confocal microscope.

\section{Plasmid transfection}

HEK293 cells and OE19 cells were subcultured on 6well plates or $35 \mathrm{~mm}$ plates for $24 \mathrm{~h}$. Superfect transfection reagent was used for HEK293 cells and lipofectamine transfection reagent was used for OE19 cells. The transfection reagent was added to the mixture of $3 \mu \mathrm{g}$ of plasmid and $200 \mu \mathrm{l}$ of reduced serum medium, mixed, and incubated for 10 minutes to allow transfection reagent/DNA complexes to form. And then the mixture was added directly to the cells. The transfected cells were cultured for $48 \mathrm{~h}$. shRNA plasmids were also delivered into cells with the same protocol and the cells were cultured for $72 \mathrm{~h}$. 


\section{Rac3 activity assay}

FBXL19-V5 transfected HEK293 and OE19 cells were cultured in 100-mm dishes and Rac3 activation was evaluated using a PBD-GTPy-Rac3 pull down assay. Briefly, cell lysates $(0.5-1 \mathrm{mg} / \mathrm{ml})$ were loaded with $10 \mu \mathrm{g}$ of PAK-1 p21-binding domain fusion-protein conjugated to agarose for $1 \mathrm{~h}$ to bind Rac3-GTP, centrifuged, and washed three times with lysis buffer. The proteins were separated by SDS-PAGE, transferred to nitrocellulose membranes, and probed with a Rac3 antibody. Total cell lysates were also probed separately with anti-Rac3 and anti- $\beta$-actin antibodies to confirm equal loading.

\section{TGF $\beta 1$ treatment}

Esophageal cancer cells were cultured in 6-well plates or $35 \mathrm{~mm}$ dishes in $10 \%$ FBS medium. After $48 \mathrm{~h}$ of transfection, the medium was replaced with $1 \mathrm{ml}$ of serum-free (blank) medium. TGF $\beta 1$ was added into the medium with the concentration range of $0,1.25,2.5,5.010 \mathrm{ng} / \mathrm{ml}$. After 4 days of incubation at $37^{\circ} \mathrm{C}$, the cells were collected and analyzed by immunoblotting with E-cadherin antibodies.

\section{Statistics}

All results were subjected to statistical analysis using twoway analysis of variance, and, wherever appropriate, analyzed by Student-Newman-Keuls test. Data are expressed as mean $\pm \mathrm{SD}$ of triplicate samples from at least three independent experiments and values that were $\mathrm{p}<0.01$ were considered statistically significant.

\section{Abbreviations}

Rac3: Ras-related C3 botulinum toxin substrate 3; UPS: Ubiquitin proteasome system; SCF: Skp1-Cullin-1-F-box protein; IL-33: Interleukin 33; GEFs: Guanidine activating proteins; GAPs: GTPase activating proteins; TGF $\beta$ : Transforming growth factor $\beta$; co-IP: Co-immunoprecipitation.

\section{Competing interests}

The authors declare that they have no competing interest.

\section{Authors' contributions}

SD performed the most experiments and prepared the manuscript; JZ, JW, RKM, AK, YZ assisted Western blotting and immunostaining; ZL, HM, JDL, AP, YZ provided financial support to SD and provided discussion; AP, RKM, YZ edit the manuscript; YZ, JZ, SD designed the experiments. All authors read and approved the final manuscript.

\section{Authors' information}

$Y Z, H M$, and $Z L$ are the corresponding authors of this work.

\section{Acknowledgements}

This study was supported by the US National Institutes of Health (R01 HL091916 and R01HL112791 to YZ), American Heart Association awards 12SDG9050005 (JZ).

\section{Author details}

'Department of Immunology, Norman Bethune College of Medicine, Jilin University, Changchun, China. ${ }^{2}$ Department of Anesthesia, First Hospital of Jilin University, Changchun, China. ${ }^{3}$ Department of Medicine and the Acute Lung Injury Center of Excellence, University of Pittsburgh, 3459 Fifth Avenue, NW 628MUH, Pittsburgh 15213, PA, USA. ${ }^{4}$ Department of Thoracic Surgery, University of Pittsburgh, Pittsburgh, PA, USA.
Received: 6 March 2014 Accepted: 25 March 2014

Published: 1 April 2014

\section{References}

1. Haataja L, Groffen J, Heisterkamp N: Characterization of RAC3, a novel member of the Rho family. J Biol Chem 1997, 272:20384-20388.

2. Walker MP, Zhang M, Le TP, Wu P, Laine M, Greene GL: RAC3 is a pro-migratory co-activator of ERalpha. Oncogene 2011, 30:1984-1994.

3. Engers R, Ziegler S, Mueller M, Walter A, Willers R, Gabbert HE: Prognostic relevance of increased Rac GTPase expression in prostate carcinomas. Endocr Relat Cancer 2007, 14:245-256.

4. Chatterjee M, Sequeira L, Jenkins-Kabaila M, Dubyk CW, Pathak S, van Golen KL: Individual rac GTPases mediate aspects of prostate cancer cell and bone marrow endothelial cell interactions. J Signal Transduct 2011, 2011:541851.

5. Gest C, Joimel U, Huang LM, Pritchard LL, Petit A, Dulong C, Buquet C, Hu CQ, Mirshahi P, Laurent M, Fauvel-Lafeve F, Cazin L, Vannier JP, Lu H, Soria J, Li H, Varin R, Soria C: Rac3 induces a molecular pathway triggering breast cancer cell aggressiveness: differences in MDA-MB-231 and MCF-7 breast cancer cell lines. BMC Cancer 2013, 13:63.

6. Bhoj VG, Chen ZJ: Ubiquitylation in innate and adaptive immunity. Nature 2009, 458:430-437.

7. Brooks CL, Gu W: Ubiquitination, phosphorylation and acetylation: the molecular basis for p53 regulation. Curr Opin Cell Biol 2003, 15:164-171.

8. Gronroos E, Hellman U, Heldin CH, Ericsson J: Control of Smad7 stability by competition between acetylation and ubiquitination. Mol Cell 2002, 10:483-493.

9. Li M, Luo J, Brooks CL, Gu W: Acetylation of p53 inhibits its ubiquitination by Mdm2. J Biol Chem 2002, 277:50607-50611.

10. Pickart CM: DNA repair: right on target with ubiquitin. Nature 2002, 419:120-121.

11. Jadhav $T$, Wooten MW: Defining an embedded code for protein ubiquitination. J Proteomics Bioinform 2009, 2:316.

12. Nandi D, Tahiliani P, Kumar A, Chandu D: The ubiquitin-proteasome system. J Biosci 2006, 31:137-155

13. Zheng $N$, Schulman BA, Song L, Miller JJ, Jeffrey PD, Wang P, Chu C, Koepp DM, Elledge SJ, Pagano M, Conaway RC, Conaway J, Harper W, Pavletich NP: Structure of the Cul1-Rbx1-Skp1-F boxSkp2 SCF ubiquitin ligase complex. Nature 2002, 416:703-709.

14. Skowyra D, Craig KL, Tyers M, Elledge SJ, Harper JW: F-box proteins are receptors that recruit phosphorylated substrates to the SCF ubiquitin-ligase complex. Cell 1997, 91:209-219.

15. Katoh M, Katoh M: Identification and characterization of FBXL19 gene in silico. Int J Mol Med 2004, 14:1109-1114

16. Zhao J, Wei J, Mialki RK, Mallampalli DF, Chen BB, Coon T, Zou C, Mallampalli RK, Zhao Y: F-box protein FBXL19-mediated ubiquitination and degradation of the receptor for IL-33 limits pulmonary inflammation. Nat Immunol 2012, 13:651-658.

17. Zhao J, Mialki RK, Wei J, Coon TA, Zou C, Chen BB, Mallampalli RK, Zhao Y: SCF E3 ligase F-box protein complex SCFFBXL19 regulates cell migration by mediating Rac1 ubiquitination and degradation. FASEB J 2013, 27:2611-2619.

18. Wei J, Mialki RK, Dong S, Khoo A, Mallampalli RK, Zhao Y, Zhao J: A new mechanism of RhoA ubiquitination and degradation: Roles of SCF E3 ligase and Erk2. Biochim Biophys Acta 2013, 1833:2757-2764.

19. Takeichi M: Cadherin cell adhesion receptors as a morphogenetic regulator. Science 1991, 251:1451-1455.

20. van Roy F, Berx G: The cell-cell adhesion molecule E-cadherin Cell Mol Life Sci 2008, 65:3756-3788.

21. Gumbiner BM: Cell adhesion: the molecular basis of tissue architecture and morphogenesis. Cell 1996, 84:345-357.

22. Field JK: Oncogenes and tumour-suppressor genes in squamous cell carcinoma of the head and neck. Eur J Cancer B Oral Oncol 1992, 28B:67-76.

23. Ruggeri B, Caamano J, Slaga TJ, Conti CJ, Nelson WJ, Klein-Szanto AJ: Alterations in the expression of uvomorulin and $\mathrm{Na}+, \mathrm{K}(+)$-adenosine triphosphatase during mouse skin tumor progression. Am J Pathol 1992, 140:1179-1185.

24. Ling ZQ, Li P, Ge MH, Zhao X, Hu FJ, Fang XH, Dong ZM, Mao WM: Hypermethylation-modulated down-regulation of $\mathrm{CDH} 1$ expression contributes to the progression of esophageal cancer. Int J Mol Med 2011, 27:625-635. 
25. Rodriguez FJ, Lewis-Tuffin $L$, Anastasiadis PZ: E-cadherin's dark side: possible role in tumor progression. Biochim Biophys Acta 2012, 1826:23-31

26. Onder TT, Gupta PB, Mani SA, Yang J, Lander ES, Weinberg RA: Loss of E-cadherin promotes metastasis via multiple downstream transcriptional pathways. Cancer Res 2008, 68:3645-3654.

27. Guilford P: E-cadherin downregulation in cancer: fuel on the fire? Mol Med Today 1999, 5:172-177.

28. Mareel MM, Behrens J, Birchmeier W, de Bruyne GK, Vleminckx K, Hoogewijs A, Fiers WC, van Roy FM: Down-regulation of E-cadherin expression in Madin Darby canine kidney (MDCK) cells inside tumors of nude mice. Int J Cancer 1991, 47:922-928.

29. Derynck R, Akhurst RJ, Balmain A: TGF-beta signaling in tumor suppression and cancer progression. Nat Genet 2001, 29:117-129.

30. Roberts $A B$, Wakefield $L M$ : The two faces of transforming growth factor beta in carcinogenesis. Proc Natl Acad Sci U S A 2003, 100:8621-8623.

31. Kim CH, Park SY, Yoo J: Expression of transforming growth factor beta1 and E-cadherin proteins in pulmonary adenocarcinoma: its significance in tumor progression. Cancer Res Treat 2013, 45:118-125.

32. Akhurst RJ, Balmain A: Genetic events and the role of TGF beta in epithelial tumour progression. J Pathol 1999, 187:82-90.

33. von Rahden BH, Stein HJ, Feith M, Puhringer F, Theisen J, Siewert JR, Sarbia M: Overexpression of TGF-beta1 in esophageal (Barrett's) adenocarcinoma is associated with advanced stage of disease and poor prognosis. Mol Carcinog 2006, 45:786-794

34. Lao-Sirieix P, Fitzgerald RC: Role of the micro-environment in Barrett's carcinogenesis. Biochem Soc Trans 2010, 38:327-330.

35. Pickart CM, Eddins MJ: Ubiquitin: structures, functions, mechanisms. Biochim Biophys Acta 2004, 1695:55-72.

36. Ridley AJ: Rho GTPases and actin dynamics in membrane protrusions and vesicle trafficking. Trends Cell Biol 2006, 16:522-529.

37. Mack NA, Whalley HJ, Castillo-Lluva S, Malliri A: The diverse roles of Rac signaling in tumorigenesis. Cell Cycle 2011, 10:1571-1581.

38. Zhu WL, Hossain MS, Guo DY, Liu S, Tong H, Khakpoor A, Casey PJ, Wang M: A role for Rac3 GTPase in the regulation of autophagy. J Biol Chem 2011, 286:35291-35298.

39. Hoeck JD, Jandke A, Blake SM, Nye E, Spencer-Dene B, Brandner S, Behrens A: Fbw7 controls neural stem cell differentiation and progenitor apoptosis via Notch and c-Jun. Nat Neurosci 2010, 13:1365-1372.

40. Klotz K, Cepeda D, Tan Y, Sun D, Sangfelt O, Spruck C: SCF(Fbxw7/hCdc4) targets cyclin E2 for ubiquitin-dependent proteolysis. Exp Cell Res 2009, 315:1832-1839.

41. Welcker M, Orian A, Jin J, Grim JE, Harper JW, Eisenman RN, Clurman BE: The Fbw7 tumor suppressor regulates glycogen synthase kinase 3 phosphorylation-dependent c-Myc protein degradation. Proc Natl Acad Sci U S A 2004, 101:9085-9090.

42. Hirshberg M, Stockley RW, Dodson G, Webb MR: The crystal structure of human rac1, a member of the rho-family complexed with a GTP analogue. Nat Struct Biol 1997, 4:147-152.

43. Harigopal M, Berger AJ, Camp RL, Rimm DL, Kluger HM: Automated quantitative analysis of E-cadherin expression in lymph node metastases is predictive of survival in invasive ductal breast cancer. Clin Cancer Res 2005, 11:4083-4089.

44. Rosivatz E, Becker I, Specht K, Fricke E, Luber B, Busch R, Hofler H, Becker KF: Differential expression of the epithelial-mesenchymal transition regulators snail, SIP1, and twist in gastric cancer. Am J Pathol 2002, 161:1881-1891.

45. Gamboa-Dominguez A, Dominguez-Fonseca C, Chavarri-Guerra Y, Vargas R Reyes-Gutierrez E, Green D, Quintanilla-Martinez L, Luber B, Busch R, Becker $\mathrm{KF}$, Becker I, Hofler H, Feng F: E-cadherin expression in sporadic gastric cancer from Mexico: exon 8 and 9 deletions are infrequent events associated with poor survival. Hum Pathol 2005, 36:29-35.

46. Hajdo-Milasinovic A, van der Kammen RA, Moneva Z, Collard JG: Rac3 inhibits adhesion and differentiation of neuronal cells by modifying GIT1 downstream signaling. J Cell Sci 2009, 122:2127-2136.

doi:10.1186/1476-4598-13-76

Cite this article as: Dong et al:: F-box protein complex FBXL19 regulates TGF $\beta$ 1-induced E-cadherin down-regulation by mediating Rac3 ubiquitination and degradation. Molecular Cancer 2014 13:76.

\section{Submit your next manuscript to BioMed Central and take full advantage of:}

- Convenient online submission

- Thorough peer review

- No space constraints or color figure charges

- Immediate publication on acceptance

- Inclusion in PubMed, CAS, Scopus and Google Scholar

- Research which is freely available for redistribution 